Tanja KAMIN, Nina PERGER*

\title{
FAILURES IN CRISIS COMMUNICATION DURING THE COVID-19 PANDEMIC IN SLOVENIA: WHAT CAN WE LEARN FROM AUDIENCE FEEDBACK?**
}

\begin{abstract}
During a pandemic, it is essential that most people respect the measures in place so as to keep the health crisis at bay. Still, a consensus must exist in society that the measures imposed by government are truly needed, just and legitimate, with several factors affecting whether this is achieved. In the article, we present the results of qualitative research (23 in-depth interviews) conducted in Slovenia at the peak of the first lockdown, focusing on how the study participants (women who were living alone during the first lockdown) perceived communication from the government and the public health authorities that comprised the official crisis communication group for managing the pandemic in Slovenia. The results present critical mistakes in communication that shaped trust in the official communicators and failed to motivate and encourage respondents to comply with the recommended and prescribed protective measures.
\end{abstract}

Keywords: Covid-19, protective measures, risk communication, trust, fear appeal, solo-living women

\section{Introduction}

To avoid repeated lockdowns, which have been driving societies to collective exhaustion, known as 'pandemic fatigue' (Meichtry et al., 2020), Gurdasani et al. (2020) point to the need to develop a sustainable Covid19 public health strategy. A key element of any pandemic control strategy concerns public health communication (Antwi-Boasiako and Nyarkoh, 2020), intended to improve awareness of the disease and protective measures and enable coordinated action to manage the spread of infections and impacts of the epidemic (Henry, 2018; Ataguba and Ataguba, 2020). Since

* Tanja Kamin, PhD, Associate Professor, Faculty of Social Sciences, University of Ljubljana, Slovenia, Nina Perger, PhD, Teaching Assistant, Faculty of Social Sciences, University of Ljubljana, Slovenia.

** The authors acknowledge the financial support from the Slovenian Research Agency (research core funding No. P5-0183). The funder played no role in study design, collection, analysis and interpretation of data neither in the decision to submit the article for publication.

DOI: 10.51936/tip.58.specialissue.517-535 
a pandemic can only be won with the cooperation of all people (Choi and Powers, 2020), for a public health communication strategy to be successful there must be a change in behaviour; namely, people acting in line with the recommended/prescribed protective measures (Nan and Thompson, 2021).

In the first wave of the pandemic, Lee (2020) reviewed the most commonly promoted behaviours directed to the general population with a view to reducing the spread of Covid-19. While some recommended behaviours were already familiar as part of basic personal hygiene (such as putting your hand over your mouth while coughing and sneezing into your elbow or a handkerchief), others were completely new, at least in the West (like wearing a face mask while around people from different households or, even more drastic, practising physical distancing ${ }^{1}$ and staying at home for an unforeseen period). These last two measures have cut deepest into the social body; interrupting daily practices, whereabouts and lifestyles and challenging the very nature of social interaction, bonding, and intimate relationships (Gostin et al., 2020), and may cause psychological distress and damage mental health (Brooks et al., 2020). This means these two measures must be introduced with special care and on the understanding that they are not always easy to follow (Guttman and Lev, 2021) and might not be followed by particular 518 groups of people at all, for example, farmers, workers in essential businesses and healthcare, homeless people, people with disabilities in need of support from neighbours or social services, and prisoners (Smith and Judd, 2020; Guttman and Lev, 2021), whereas for some social groups the psychological costs of fully abiding by these measures could just be too high.

A recent study (Kamin et al., 2021) demonstrates that people respond to preventive measures on three different levels: cognitive, affective and behavioural. These three levels of responses are not always aligned; on the contrary, they might be conflicting and lead people to uncomfortable dissonances. An individual might understand and agree with a measure, but since complying with it entails a huge affective burden, they might sometimes downplay the measure's importance and adapt the recommended behaviour in such a way that is psychologically easier to follow (for more on cognitive dissonance and negative affect, also see Harmon-Jones, 2000; for a wider discussion on emotion in health behaviour science, also see Williams and Evans, 2014). The quintessential importance of the complex web of cognitive, affective and behavioural responses to preventive measures holds important implications for communication strategies that aim to encourage behaviour change and/or maintenance with regard to Covid-19

1 Officially also known as 'social distancing', physical distancing was recognised as an effective measure to slow the spread of Covid-19 down by keeping a distance of 1.5-2 $\mathrm{m}$ from people not members of one's household, and by limiting or prohibiting interactions with people outside of one's household (CDC, 2020, July 15; WHO, n.d.). 
protective measures and should be given more attention while designing communication strategies for managing the pandemic (Williams and Evans, 2014).

Despite the vast corpus of knowledge about behaviour-change approaches and crisis-health communication (Jones et al., 2010; Henry, 2018; French and Gordon, 2019; Lee, 2020; Nan and Thomson, 2020), official communications about Covid-19 were quite cumbersome and uncoordinated during the pandemic's first wave (Noar and Austin, 2020; Smith and Judd, 2020). Research shows that public health messages have to be acceptable, credible and trustworthy to be effective; they need to increase the public's understanding and perceptions of the threat and contribute to empowerment processes that enable people to perform the recommended behaviours (Ghio et al., 2020; Noar and Austin, 2020; Olagoke et al., 2020; Ihm and Lee, 2021). Failure to communicate according to these standards limits the measures' potential to flatten the infection curve, especially because this pandemic is a very specific situation: knowledge of the virus is still being developed; outbreaks occur in unanticipated ways; and there are many uncertainties about the scope of the measures and anticipated results, which may lead to confusion. In addition, the lack of clear and consistent communication that is not performed with the public in a transparent and respectful manner triggers mistrust and reduced confidence in those who design the measures and communicate about them. The absence of trust in public institutions is already a problem in normal circumstances, but may bring particularly devastating consequences during a crisis because individuals who do not trust the public institutions that design the measures and communicate about them follow those measures less strictly than others who trust such institutions (Hafner-Fink and Uhan, 2020). One reason for this is that when people do not trust institutional communication about the measures, they experience lower self-efficacy while carrying out the recommended behaviours (Olagoke et al., 2020).

The public is not a homogeneous mass of people that can be addressed with a simple 'one-size-fits-all' measure and message. Instead, specific populations might either be more at risk and/or difficult to reach, which requires tailoring strategies to disseminate accurate information via diverse distribution channels of relevance to selected populations (Choi and Powers, 2020; Guttman and Lev, 2021; Ihm and Lee, 2021), with special attention paid to marginalised social groups (Semino, 2021). One social group that has been overlooked during the Covid-19 pandemic is those who live alone, despite their numbers growing (Chandler et al., 2004; Roseneil, 2006; Klinenberg, 2012; Demey et al., 2013; Jamieson and Simpson, 2013). For people living in single households, living alone has become literal during the lockdowns, suggesting that certain preventive measures were not designed with the 
socio-economic diversity of households and habitation lifestyles of different people in mind. This failure to consider various social and lifestyle circumstances while designing and implementing measures is also reflected in communication, leaving particular audiences unaddressed, left out and forgotten in their struggle to comply with (at least some of) the measures.

In this article, we consider how the Slovenian public has received the official authorities' communication regarding the Covid-19-related measures coordinated by the government, especially focusing on the views of the above-mentioned overlooked group of people. We present the results of research we conducted during the first lockdown in Slovenia with 23 women who were living alone at the time of the lockdown.

The leading research question was: What did the study participants think about and how did they make sense of the official communication on the Covid-19-related protective measures in Slovenia? We aim to demonstrate the crucial elements of the official crisis communication that eroded trust in the official communicators and failed to motivate and encourage the respondents to abide by the recommended/prescribed protective measures.

520 Method

\section{Selection Process and Sampling}

We employed a mixed purposeful sampling approach entailing both convenience and snowball sampling. A written invitation distributed through researchers' social networks encompassed the stated purpose of the study, the research approach, the participants' rights and researchers' obligations to broaden the search for potential participants' contact information. To diversify the study sample, we purposefully selected female participants with different demographic variables (such as age, place of residence, occupation).

To determine an adequate sample size, we followed the principles of theoretical sampling (Starks and Trinidad, 2007), Braun and Clarke's (2013) guidelines for thematic analysis, Hennink, Kaiser and Marconi's (2017) guidelines on saturation in codes and meanings, and the criteria of information power of Malterud et al. (2016). The final sample thus consists of 23 interview participants.

\section{Data Collection}

We collected the data with in-depth, semi-structured, face-to-face interviews, which were conducted via online platforms due to physical-distancing 
measures. All participants signed an informed consent form. All of the interviews, each lasting on average 2 hours, were audio recorded and transcribed verbatim. They were conducted by the researchers between 3 and 15 April 2020, namely the third and fourth weeks of the first Covid19-related lockdown in Slovenia. The participants' personal characteristics were anonymised to guarantee confidentiality. In all stages of the research process, we followed The code of ethics for researchers of the University of Ljubljana [Etični kodeks za raziskovalce Univerze v Ljubljani] (2014).

\section{Participants}

The participants' average age in years was 45.5 (the median was 44), with the youngest being 25 and the oldest 69. The majority (17) of the interviewees were living in the capital, while the others lived in smaller towns or villages around Slovenia. The majority (18) of participants had completed higher education. This is in line with other studies showing that in countries with a Christian-European legacy, well-educated and professional women are disproportionately represented among women who live alone (Demey et al., 2013; Jamieson and Simpson, 2013: 51). Three participants were retired, three were self-employed, one had been unemployed since the pandemic started, one was a student with a state scholarship while the others were employed under either permanent or temporary contracts. One was employed, but her contract was on hold during the pandemic. Four participants earned between EUR 600 and 1,000 net per month, and 19 earned between EUR 1,000 and 3,000 net. Three participants were in an intimate relationship ( 2 were in a long-distance relationship, and 1 had a partner who lived in Slovenia but in another city), the rest of them were (currently) without partners, and some having been so for many years ( 2 participants were widowed, 5 divorced, and 13 had never been married).

\section{Data Analysis}

We analysed the collected data in the Slovenian language with the MaxQDA2020 software (VERBI Software, 2019). We started the analysis by following the principles of the grounded theory of Strauss and Corbin (1998), aiming to draw codes and categories directly from the data. First, we read the transcripts several times and prepared a set of initial observations. We then looked for patterns in the data, working towards developing an understanding able to explain those patterns in the sample and developing a more general set of propositions. Led by the guidelines introduced by Braun and Clarke (2006), we identified and described core themes across the data. Each identified issue raised by the participants was given a code 
name (in vivo coding). We developed a definition for each code and established clear distinctions between them as we listed them in the codebook. The coding process, framework and results were discussed and elaborated among the authors, assuring the reliability of the findings.

\section{Results}

Most of the protective measures related to Covid-19 introduced novel circumstances. Our respondents mostly obtained information about them through the media and mediated press conferences held by a spokesperson for the government and selected public health authorities. In this article, we consider what the respondents thought and how they made sense of and felt about the official communication about the Covid-19-related protective measures in Slovenia and analyse how this can help in understanding their behaviour with regard to the recommended/prescribed protective measures.

First, we present the different categories of the participants' responses to the Covid-19-related official communication, namely: 1) communication frame; 2) perceived credibility of the communication source; and 3)

522 overwhelming risk communication and communicated measures. Second, we present relationships among these categories and in a discussion aim to build a more general set of propositions about the (in)effectiveness of the communication of the government and the public health authorities that comprised the official crisis communication group for managing the pandemic in Slovenia.

\section{Communication Frame}

The respondents perceived the official Covid-19-related communication to be very problematic; as grounded in a rhetoric of fear rather than encouragement and as patronizing the public and applying stigmatisation strategies rather than strategies for building up collective solidarity and responsibility.

\section{Rhetoric of Fear}

The majority of our respondents were following the domestic and foreign official crisis communication about Covid-19 and were familiar with different approaches to handling the situation. They acknowledged the good communication strategies of certain other countries, with New Zealand and its prime minister being the most frequently mentioned, and they evaluated the Covid-19 communication of Slovenian officials against those standards. 
By having 'second-hand' experience with crisis communication implemented elsewhere, the study respondents exposed the inappropriate use of the rhetoric of fear and lack of communication that would reassure the people that the nation, through a collective effort, would manage to deal with the epidemic successfully and that would encourage them to cooperate by complying with the recommended measures. The prevalence of the rhetoric of fear raised several issues that might have made the Covid-19-related communication less effective in Slovenia. One concerns the growing mistrust in those institutional actors and representatives who were responsible for informing the public about the Covid-19 pandemic and protective measures in Slovenia, while the other is about the lack of safety experienced, as demonstrated in the following quote:

It is not science fiction ... that I do not feel safe, that I don't trust people who deliver the information because they deliver it in a manner that scares, even though they could deliver it in a manner that 'we are all in this together', as the leaders of some other places have demonstrated is possible. (Respondent 2)

The respondents acknowledged that the virus and the whole pandemic situation were novel and that a lack of knowledge and initial mistakes in managing the situation were to be expected (and excused). They understood that the government, the public health institutions as well as the media did not have available all of the essential information and expertise and were forced to improvise and act based on information they were receiving on a daily basis. The applied rhetoric of fear was perceived as unnecessary, dysfunctional and unsuccessful, especially when intertwined with metaphors of war:

I know that the media is under awful pressure, that it is difficult to update [the information] at such a fast pace, that many things must be taken into account, but this communication, as if we are on a battlefield and are counting the dead, is absolutely inappropriate for the pandemic. The crisis communication as we experience it just doesn't hold water. (Respondent 6)

The rhetoric of fear in combination with war metaphors gave rise to affective tensions which our respondents connected to the crisis communication, which gradually made it unbearable to follow:

No, I stopped [following it]. As soon as the government changed, I stopped because I couldn't watch them. I get so irritated with this horrible 
rhetoric. I really don't know why I should watch [ the government spokesperson]. (Respondent 2)

\section{Lack of Respect for the Public: Patronising and Stigmatisation}

In addition to the rhetoric of fear, two respondents stressed the lack of respect shown towards the public in the official crisis communication. They criticised the government's communication that addressed members of the public as if they were clueless and disobedient children in need of parental authority and control, as the respondent below vividly expressed:

What bothers me with this government is that they are using their communication channels, all that I followed, even Twitter, to show their position. It bothers me that they show this attitude as if we were 6-year-olds going wild. (Respondent 7)

Another respondent emphasised the official crisis communication's stigmatising nature. Pointing the finger at specific population groups without 524 evidence and blaming them for the worsening epidemic situation created unnecessary social tension (and divisions). Rather than grounded in expertise, the protective measures related to limiting individuals' movements to the municipality of their residence were grounded in depicting residents of the capital city as irresponsibly spreading the virus across Slovenia:

You cannot demonise the inhabitants of Ljubljana, who allegedly are walking around Slovenia and spreading the virus. This only builds on discomfort and anxiety. So ... miscommunication is a problem and the way this virus-related problem is presented. (Respondent 6)

\section{Ambiguity and Inconsistency of the Protective Measures and Communication about Them}

The respondents found the official crisis communication and the protective measures themselves to be inconsistent and ambiguous. Not only could the respondents not see the logic and relevance of certain protective measures, they were also troubled by the inconsistent implementation of some of them. For example, while some services like libraries were closed down, others like stores were kept open, despite the risk of Covid-19 infection being perceived as similar or the same in these places, as underscored by the following respondent: 
The libraries, bookshops and public talks ... were closed down before the shops. If we can go to food stores, where many more people go than bookshops, museums and libraries, why wouldn't we also open those and other shops? I don't understand. I don't see any logic in this. (Respondent 7)

The perceived transparency of introducing and enforcing some protective measures was further undermined by the government when it added exceptions to the measures and rules already implemented in a way and with a frequency that made no sense to the respondents. For example, crossing the borders of municipalities was forbidden, but an exception was then introduced for the owners of weekend residences, which was seen as unjust and favouring better-off citizens:

And these statements, that they will ease the measures for the owners of weekend residences ... Wait a minute! [laugh] What about the rest of us, who do not have properties all around Slovenia? Can we take a trip? (Respondent 10)

\section{Perceived Credibility of the Communicator}

The perception that the official crisis communication was inappropriate due to the communication approach chosen (rhetoric of fear, war metaphors, patronising of the public, stigmatisation of particular social groups, non-transparent introduction of the measures and exceptions to the rules) gradually raised doubts as to the credibility and truthfulness of the official Covid-19-related communicators per se, especially when combined with the perceived lack of coordinated action and the increasing absence of epidemiological expertise in designing, implementing and communicating the protective measures.

\section{Exclusion of the Fields of Expertise}

Some respondents perceived the medical experts, especially epidemiologists, as having been side-lined and ignored when protective measures were being designed and explained, as the next respondent noted:

... the government maybe doesn't listen to the experts enough. While the experts had already called for action about the need to wear protective facial masks, the government was lagging behind. This informing ... it's like a kindergarten. (Respondent 11) 
Almost all respondents perceived the protective measures introduced as insufficiently supported by scientific evidence and expert explanation. If this was accepted (and excused) early on in the lockdown due to the lack of knowledge about the nature of the novel virus, it became troubling over time, making it challenging for our respondents to both follow the official communication about the introduced measures and comply with the measures. Further, the governmental protective strategies' perceived absence of being grounded in thoroughly expert knowledge led the respondents to gradually abandon the governmental sources of crisis communication and turn to other, unofficial sources of expert information about Covid-19 issues that were emerging parallel to the public-institutional ones (for example, Sledilnik).

\section{Politicisation of the Fields of Expertise}

The feeling that expertise (authorities from particular expert fields) has been excluded from designing, implementing and communicating the Covid-19-related protective measures left our respondents with the uncomfortable impression that the experts who remained in the government's

526 group for handling the crisis, and their judgements, had become politicised. Here, the respondents divided experts into those scientifically independent and those subordinated to politics, namely: a) expertise perceived as expert; and b) expertise perceived as nonexpert. The latter was seen as being politically placed in the centre of the Covid-19-related crisis communication and, thereby, considered to be less trustworthy. One respondent explained:

There is something else that really bothers me: the politicisation of the medical/healthcare expertise. This really bothers me. Here, they don't allow epidemiologists to step onto the front lines ... and that is a catastrophe. That there is one medical doctor from [a hospital], who is a specialist in radiology, lecturing on television. That there is only one epidemiologist... [in the government's group for handling the crisis] is a catastrophe /.../ Expertise is side-tracked, totally. Politics makes decisions now. (Respondent 13)

\section{Exploitation of the Epidemic for Political Purposes}

The perception of expertise having been excluded and/or politicised triggered concerns that the epidemic was being exploited for political and ideological reasons. Our respondents perceived that the epidemic was giving certain political players opportunities to advance particular 
political interests. Some respondents expressed difficulties with drawing a line between expert-driven and evidence-based strategies for handling the epidemic and political manoeuvres for strengthening political power. This lowered the trust in the communicated protective measures and the (remaining) experts:

What is crucial is that I can't distinguish between the measures - which are truly needed and those that suit them [the government]. I find this very problematic, and that's what is the source of my frustration ... that nobody explains why we need to shut down the whole state in the sense of limiting free movement between municipalities. Why not only the hot spots? ... In a nutshell, I really miss this, some things, and that's why my trust has been damaged. (Respondent 6 )

For me, these are experts - people whose occupation this is. If we don't listen to them, then I really don't know what to read and why I would listen. It is also true that it became obvious that even the experts were not equally expert. (Respondent 2)

\section{Overwhelming Risk Communication and Communicated Measures}

Our respondents expressed doubts in the protective measures due to the way they were implemented and communicated. Still, it should be noted that they reported on having fully respected them, at least for a limited period (also see Kamin et al., 2021). Most protective measures were seen as necessary for 'flattening the curve'. Yet, those measures that did not make sense to the respondents or were experienced as unjustified were reportedly more challenging to completely respect. Not seeing particular measures as evidence-based and supported by a proper explanation led the respondents to experience a certain dissonance. Cognitively, they were generally supportive of the need for some protective measures to be put in place, yet they also expected to be provided with a plausible explanation for the introduction of the measures, which would help them understand their underlying logic:

I totally trust the measures ... the measures that are necessary and are not related to left or right politics. I don't have a problem with that. I also don't have a problem if the measures that are put in place are also properly explained. (Respondent 15) 
The intertwined web of perceived problematic features of crisis communication and the perceived untrustworthy nature of the communicators shaped how our respondents experienced and felt not only about the official crisis communication but also about the measures themselves. The majority reported experiencing the official communication as a source of frustration, fear, anger, anxiety and depression, and those affective resonances made it harder to regularly follow the official updates on the Covid19 situation:

For example, I don't watch television, [journalistic] expertise, because it seems that the level [of professionalism] has fallen to such a low point that I simply can't digest it. Because it's not about reporting either on corona or migration streams before that, but it is about provoking distress, fear, nervousness. .. This information madness about coronavirus is, in my opinion, an abuse of the situation for something shocking, horrible, horrifying. (Respondent 15)

Crisis communication is supposed to assist in easing the affective response to a crisis, to reassure people about accepting the limitations and encourage them to believe in the crisis' passing nature. A crucial findings of this study is, however, that the official Covid-19 communicators managed to do the opposite and in fact added to the affective burden of the pandemic. Rather than the communication being experienced as motivating, calming and calling for collective solidarity and responsibility, it was experienced as an additional source of frustration, discomfort, anxiety, depression and anger. For some, the affective manifestation of cognitive dissonance gave rise to an amorphous affective resistance and opened up the possibility to oppose the measures, as evident in the quote below:

I am constantly asking myself, on the one hand, of course, [having protective measures in place] is fine because we care about health but, on the other hand, all the time, because of these strange measures, which the government implements, I mean, strange - they accept hundreds of stupid things, and then all these measures, like municipalities and social distancing, in some way ... a person would almost want to resist all of these. Despite knowing that this is good for health, it also gets on your nerves because these are governmental pressures, and you are unsure how much to trust them, how much is really needed or not. (Respondent 12)

The respondents reported having generally respected the measures but doing so with more affective burdens due to the difficulties expressed with the official Covid-19-related communication. 


\section{Discussion}

The extent to which Covid-19-related measures are respected depends on people's responses to them on cognitive, affective and behavioural levels. Affective responses seem to be crucial factors in actual behaviour (change) and deserve special attention while designing the communication strategy for managing the pandemic, especially when we wish to encourage people to comply with the measures (and behaviours) for a longer period (Harmon-Jones, 2000; Williams and Evans, 2014; Kamin et al., 2021).

Our research shows that the communication from the government and the public health authorities that comprised the official crisis communication group for managing the pandemic in Slovenia failed to meet the basic standards for effective public health communication (to be acceptable, credible and trustworthy; to increase the public's understanding and perceptions of the threat; and to contribute to empowerment processes that would enable people to perform the recommended behaviours) (Ghio et al., 2020; Noar and Austin, 2020; Olag, 2020; Ihm and Lee, 2021). The government's crisis communication group was not perceived as communicating about the protective measures in a consistent, coherent and calming way. It failed to address the public respectfully, calm it down, reassure it and motivate it to follow the measures. Instead, the official crisis communication group added to the ambiguities, exacerbating the already uncertain situation and starting to destroy the credibility of the official crisis communication sources. Our respondents gradually stopped trusting the official sources and, by the time of our fieldwork, they were already noting the lack of a credible source of information about the Covid-19 situation in Slovenia. They were turning away from the official crisis communication sources and searching for alternative, more trustworthy sources (such as articles written by experts, reports published in foreign media or data-based information channels, such as Sledilnik) to help them better understand and cope with the situation without the additional emotional pressure produced by the use of the rhetoric of fear in the official crisis communication.

Framing the official communication about Covid-19 with metaphors of war and the rhetoric of fear might be an effective initial step in crisis communication, when the threat is novel and the issue needs full and immediate political attention, coordinated intervention and cooperation from all members of society. War metaphors draw on well-defined schematic knowledge, conveying a sense of risk and urgency, bringing on fear and anxiety due to the high stakes and tremendous risks, such as the loss of life and resources, and inducing feelings of despair (Flusberg et al., 2018). However, war framing can backfire and even be harmful if it proceeds in an overly negative way (as shown in our findings) or emphasised over a long period 
(Flusberg et al., 2018). Research on the effectiveness of fear appeals, which are "persuasive messages designed to scare people by describing the terrible things that will happen to them if they do not do what the message recommends" (Witte, 1992: 329), reveals consensus only on the following conditions: fear appeals can positively motivate behaviours if used for a limited amount of time and for certain behaviours, primarily those that one can have control over (Witte et al., 2000; de Pelsmacker et al., 2011). Researchers and practitioners also seem to agree that fear appeals are counterproductive and can contribute to defensiveness, avoidance, reactance and denial in response to the recommendation (Witte et al., 2000). The effectiveness of fear appeals depends on too many factors that are difficult to control in the long run and on a larger social scale. The effectiveness of fear appeals is an outcome of the interaction between fear (emotion with a high level of arousal), perceived threat (cognition related to perceived susceptibility to the threat and perceived severity of the threat) and perceived efficacy (cognition related to perceived self-efficacy and perceived response efficacy) (Witte et al., 2000; Loewenstein et al., 2001; Williams and Evans, 2014). In our research, we identified that respondents did feel fear (along with other negative emotions) with regard to the Covid-19-related threat; they did per-

530 ceive themselves as susceptible to the threat of becoming sick or infecting others; and they did perceive the great severity of the threat, especially at the start of the pandemic. This part of the equation works in favour of the rhetoric of fear used in the official Covid-19-related risk communication in Slovenia. However, we identified several issues on the side of perceived efficacy, namely with the respondents' beliefs in their ability to comply with the recommended responses to the measures (perceived self-efficacy) and their beliefs in whether the recommended responses are working to prevent the threat (perceived response efficacy).

According to the fear appeal theory (Witte et al., 2000), perceived efficacy determines whether people will become motivated to control the danger of the threat or control their fear about the threat. If our respondents believed they were able to effectively perform a recommended response against Covid-19, they would be motivated to control the danger and think about the recommended measures as ways to remove or lessen the threat of infection with the coronavirus. They would think carefully about the recommended behaviours advocated in the official crisis communication and adopt those behaviours to control the danger. Yet, our respondents gradually developed doubts in whether some measures and related recommended behaviours were really working (low perceived response efficacy) and/or whether they were able to behave according to the measures (low perceived self-efficacy), and they became more concerned with how to control their fear (and other negative affects triggered by the official 
Covid-19-related communication, such as anger and frustration), while they gradually focused on eliminating their fear and other negative affects through various strategies, even denial (e.g. "I'm not at risk of getting sick if I don't constantly follow all of the measures"), defensive avoidance (e.g. "This is just too frustrating; I'm simply going to avoid this communication"), or reactance (e.g. "The government is just trying to manipulate me; I'm going to disregard its communication and its measures").

This study has some limitations, primarily due to the specific, quite homogenous sample. More conclusive findings could emerge by expanding the sample and including informants of different genders, social class and socio-economic background. A quantitative study involving a larger sample might be appropriate for validating our findings. At the same time, our research findings could be used to validate and deepen understanding of data collected in quantitative research about trust in political institutions during the pandemic's first wave in Slovenia (Hafner-Fink and Uhan, 2020).

\section{Conclusion}

In this article, we have presented how women who were living alone at the time of the first lockdown thought about and made sense of the official communication about the Covid-19-related protective measures in Slovenia. Our study shows how important it is to communicate about the measures in a respectful, trustworthy, sensible and encouraging manner, especially in circumstances where lives depend on the ways people react to public health measures. There is no excuse for some of the poor communicative approaches of the government and the public health authorities that make up the official crisis communication group for managing the pandemic in Slovenia. These approaches include the treatment of the public (citizens of Slovenia) in a way perceived to be disrespectful; (non)cooperation with experts in such a way that it was seen as exclusionary and politicised; and the lack of explanation for the measures introduced, which gave the impression the pandemic was being exploited for political ends. All of these communication mistakes lowered the trust in public institutions, which was already low in Slovenia (Hafner-Fink and Uhan, 2020), and could significantly jeopardise effective handling of the current and future waves of the pandemic.

Many other problematic issues with respect to the officials' communication approaches could have been avoided by following the protocols of health risk communication and with better knowledge of behaviour change theory, including the use of the rhetoric of fear which does not achieve a mobilising effect but a paralysing one. The rhetoric of fear can only be effective in achieving behaviour change and/or maintenance when it is accompanied by communication that strengthens perceived efficacy, thereby 
encouraging target populations to believe they are able to behave according to the Covid-19 protective measures and that the recommended behaviours actually work to minimise the infection threat. Still, to accomplish this, the officials would need to identify and acknowledge the barriers that inhibit people's perceived ability to behave in line with the measures and directly address those barriers (like perceived material/psychological/social costs, skills, knowledge, beliefs) in their crisis communication. Moreover, they should clearly explain how following certain measures lowers the chances of becoming infected or spreading infection. Finally, the pandemic simply cannot be resolved without the cooperation of the whole population, which means the positive behaviours of people must be recognised, praised and rewarded if they are to be motivated to maintain those behaviours in our case, respecting the Covid-19-associated protective measures for a prolonged period. Governments and their official communicators must consider the costs and barriers related to Covid-19-related protective measures for different groups of people and respectfully acknowledge people's efforts. They should also pay more attention to communication tactics that would help people deal with their affective responses to the measures introduced. People need rational appeals when in the contemplation stage, and 532 fear appeals, too, for a limited time can play a successful role in bringing them closer to the action stage. However, in the long run and for sustaining behaviour change, people must also be addressed by strong, personally relevant and positive emotional appeals that stress the benefits of them for them individually and collectively from changing their behaviour.

\section{BIBLIOGRAPHY}

Antwi-Boasiako, Joseph and Enoch Nyarkoh (2020): Government Communication During the Covid-19 Pandemic: The Case of Ghana. International Journal of Public Administration.

Ataguba, A. Ochega and John E. Ataguba (2020): Social Determinants of Health: The Role of Effective Communication in the Covid-19 Pandemic in Developing Countries. Global Health Action 13 (1): 1-5.

Braun, Virginia and Victoria Clarke (2006): Using Thematic Analysis in Psychology. Qualitative Research in Psychology 3 (2): 77-101.

Braun, Virginia and Victoria Clarke (2013): Successful Qualitative Research: A Practical Guide for Beginners. London: Sage Publications Ltd.

Brooks, K. Samantha, Rebecca K. Webster, Louise E. Smith, Lisa Woodland, Simon Wessely, Neil Greenberg and Gideon J. Rubin (2020): The Psychological Impact of Quarantine and How to Reduce It: Rapid Review of the Evidence. The Lancet 395 (10227): 912-920.

Chandler, Joan, Malcom Williams, Moira Maconachle, Tracey Collett and Brian Dodgeon (2004): Living Alone: Its Place in Household Formation and Change. Sociological Research Online 9 (3): 42-54. 
Choi, Seongwon and Thomas L. Powers (2020): Covid-19: Lessons from South Korean Pandemic Communications Strategy. International Journal of Healthcare Management 14 (1): 271-279.

Demey, Dieter, Ann Berrington, Maria Evandrou and Jane Falkingham (2013): Pathways into Living Alone in Mid-Life: Diversity and Policy Implications. Advances in Life Course Research 18 (3): 161-174.

de Pelsmacker, Patrick, Verolien Cauberghe and Nathalie Dens (2011): Fear Appeal Effectiveness for Familiar and Unfamiliar Issues. Journal of Social Marketing 1 (3): 171-191.

Flusberg, J. Stephen, Teenie Matlock and Paul H. Thibodeau (2018): War Metaphors in Public Discourse. Metaphor and Symbol 33 (1): 1-18.

French, Jeff and Ross Gordon (2019): Strategic Social Marketing: For Behaviour and Social Change. London: SAGE Publications Ltd.

Ghio, Daniela, Sadie Lawes-Wickwar, Mei Yee Tang, Tracy Epton, Neil Howlett, E. Jenkinson ... and Chris Keyworth (2020, July 13): What Influences People's Responses to Public Health Messages for Managing Risks and Preventing Infectious Diseases? A Rapid Systematic Review of the Evidence and Recommendations.

Gostin, O. Lawrence, Eric A. Friedman and Sarah A. Wetter (2020): Responding to COVID 19: How to Navigate a Public Health Emergency Legally and Ethically. Hastings Center Report 50 (2): 8-12.

Guttman, Nuritt and Eimi Lev (2021): Ethical Issues in Covid-19 Communication to Mitigate the Pandemic: Dilemmas and Practical Implications. Health Communication 36 (1): 116-123.

Gurdasani, Deepti, Laura Bear, Debby Bogaert, Rochelle A. Burgess, Reinhard Busse, Roberto Cacciola, ... and H. Ziauddeen (2020): The UK Needs a Sustainable Strategy for Covid-19. The Lancet 396 (10265): 1800-1801.

Hafner-Fink, Mitja and Samo Uhan (2020): Life and Attitudes of Slovenians during the Covid-19 Pandemic: The Problem of Trust. International Journal of Sociology 51 (1): 76-85.

Harmon-Jones, Eddie (2000): Cognitive Dissonance and Experienced Negative Affect: Evidence that Dissonance Increases Experienced Negative Affect Even in the Absence of Aversive Consequences. Personality and Social Psychology Bulletin 26 (12): 1490-1501.

Hennink, M. Monique, Bonnie E. Kaiser and Vincent C. Marconi (2017): Code Saturation Versus Meaning Saturation: How Many Interviews Are Enough? Qualitative Health Research 27 (4): 591-608.

Henry Bonnie (2018): Canadian Pandemic Influenza Preparedness: Communications Strategy. Canada Communicable Disease Report 44 (5): 106-109.

Ihm, Jennifer and Chul-Joo Lee (2021): Toward More Effective Public Health Interventions during the Covid-19 Pandemic: Suggesting Audience Segmentation Based on Social and Media Resources. Health Communication 36 (1): 98-109.

Jamieson, Lynn and Roona Simpson (2013): Living Alone: Globalization, Identity and Belonging. London: Palgrave Macmillan. 
Jones, C. Sandra, Louise Waters, Omnia Holland, John Bevins and Donald C. Iverson (2010): Developing Pandemic Communication Strategies: Preparation without Panic. Journal of Business Research 63 (2): 126-132. Accessible at https:// ro.uow.edu.au/ hbspapers/3387, 14. 12. 2020.

Kamin, Tanja, Nina Perger, Liza Debevec and Blanka Tivadar (2021): Alone in a Time of Pandemic: Solo-Living Women Coping with Physical Isolation. Qualitative Health Research 31 (2): 203-217.

Klinenberg, Eric (2012): Going Solo: The Extraordinary Rise and Surprising Appeal of Living Alone. London: Penguin Books Ltd.

Lee, A. Sherman (2020): Coronavirus Anxiety Scale: A Brief Mental Health Screener for Covid-19 Related Anxiety. Death Studies 44 (7): 393-401.

Loewenstein, F. George, Eike U. Weber, Christopher K. Hsee and Ned Welch (2001): Risk as Feelings. Psychological Bulletin 127 (2): 267-286.

Malterud, Kirsti, Volkert D. Siersma and Ann D. Guassora (2016): Sample Size in Qualitative Interview Studies: Guided by Information Power. Qualitative Health Research 26 (13): 1753-1760.

Nan, Xiaoli and Teresa Thompson (2021): Introduction to the Special Issue on "Public Health Communication in an Age of Covid-19". Health Communication 36 (1): $1-5$.

Noar, M. Seth and Lucinda Austin (2020): (Mis)communicating about Covid-19: Insights from Health and Crisis Communication. Health Communication 35 (14): 1735-1739.

Olagoke, A. Ayokunle, Olakanmi O. Olagoke and Ashley M. Hughes (2020): Psychological Pathways Linking Public Trust During the Coronavirus Pandemic to Mental and Physical Well-being. Frontiers in Psychology 11.

Roseneil, Sasha (2006): On Not Living with a Partner: Unpicking Coupledom and Cohabitation. Sociological Research Online 11 (3): 111-124.

Semino, Elena (2021): "Not Soldiers but Fire-fighters" - Metaphors and Covid-19. Health Communication 36 (1): 50-58.

Smith, A. James and Jenni Judd (2020): COVID 19: Vulnerability and the Power of Privilege in a Pandemic. Health Promotion Journal of Australia 31 (2): 158-160.

Starks, Helene and Susan B. Trinidad (2007): Choose Your Method: A Comparison of Phenomenology, Discourse Analysis, and Grounded Theory. Qualitative Health Research 17 (10): 1372-1380.

Strauss, Anselm and Juliet Corbin (1998): Basics of Qualitative Research: Techniques and Procedures for Developing Grounded Theory. Thousand Oaks: Sage Publications Inc.

Williams, M. David and Daniel R. Evans (2014): Current Emotion Research in Health Behaviour Science. Emotion Review 6 (3): 277-287.

Witte, Kim (1992): Putting the Fear Back into Fear Appeals: The Extended Parallel Process Model. Communications Monographs 59 (4): 329-349.

Witte, Kim and Mike Allen (2000): A Meta-Analysis of Fear Appeals: Implications for Effective Public Health Campaigns. Health Education and Behavior 27 (5): 591-615. 


\section{SOURCES}

Centers for Disease Control and Prevention (2020): Social distancing. Accessible at https://www.cdc.gov/coronavirus/2019-ncov/prevent-getting-sick/socialdistancing.html, 1. 12. 2020.

Etični kodeks za raziskovalce Univerze v Ljubljani [The code of ethics for researchers of the University of Ljubljana] (2014): University of Ljubljana. Accessible at https://www.uni-lj.si/raziskovalno_in_razvojno_delo/etika_v_raziskovanju/, 1. 1. 2021.

Meichtry, Stacy, Joanna Sugden and Andrew Barnett (2020): Pandemic Fatigue Is Real - and It's Spreading. Wall Street Journal 26 Oct 2020. Accessible at https:// www.wsj.com/articles/pandemic-fatigue-is-realand-its-spreading-11603704601, 15. 1. 2021.

VERBI Software (2019): Maxqda2020 [Computer software]. Verbi Software. Accessible at https://www.maxqda.com, 15. 1. 2021.

World Health Organization (n.d.): Covid-19: Physical distancing. Accessible at https://www.who.int/westernpacific/emergencies/covid-19/information/physical-distancing, 1. 12. 2020. 